\title{
Single-stage definitive surgical treatment for portal biliopathy
}

\author{
M M Bernon, ${ }^{1}$ MB BCh, FCS (SA), Cert Surg Gastroenterol (SA); M W Sonderup, ${ }^{2}$ MB ChB, FCP (SA), MMed; \\ G E Chinnery, ${ }^{1} \mathrm{MB} \mathrm{ChB}, \mathrm{FCS}(\mathrm{SA})$, Cert Surg Gastroenterol (SA); \\ P C Bornman, ${ }^{1}$ MB ChB, MMed, FRCS (Edin), FRCS (Glasg), FCS (SA); J E J Krige, ${ }^{1}$ MB ChB, MSc, FACS, FRCS, FCS (SA) \\ ${ }^{1}$ HPB and Surgical Gastroenterology Unit, Groote Schuur Hospital and Department of Surgery, Faculty of Health Sciences, \\ University of Cape Town, Cape Town, South Africa \\ ${ }^{2}$ Division of Hepatology, Department of Medicine, Groote Schuur Hospital and Faculty of Health Sciences, \\ University of Cape Town, Cape Town, South Africa
}

Corresponding author: M M Bernon (marcbernon@mail.com)

The term portal biliopathy $(\mathrm{PB})$ is used to describe the biliary abnormalities associated with portal hypertension. Between $5 \%$ and $30 \%$ of patients with PB develop biliary obstruction. We report on a patient with extrahepatic biliary obstruction caused by PB that was successfully managed with an intrahepatic segment 3 bypass. The traditional surgical approach for a patient with extrahepatic biliary obstruction caused by PB would be a portosystemic shunt followed by a hepaticojejenostomy if the jaundice persisted. An intrahepatic segment 3 bypass provides definitive treatment ensuring biliary decompression and stone removal in a single procedure in appropriately selected patients.

S Afr J Surg 2014;52(2):57-60. DOI:10.7196/SAJS.2062

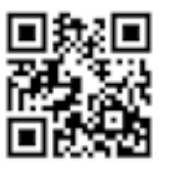

The term portal biliopathy $(\mathrm{PB})$ is used to describe the biliary abnormalities associated with portal hypertension. PB can occur in any patient with portal hypertension, but is usually associated with extrahepatic portal venous obstruction (EHPVO). Biliary abnormalities occur in $81-100 \%$ of patients with EHPVO, but only $5-30 \%$ of patients develop biliary obstruction. The extent of the PB varies from isolated extrahepatic to diffuse intra- and extrahepatic biliary strictures. ${ }^{[1-5]}$

The management of $\mathrm{PB}$ is complex in patients who present with variceal bleeding and clinically significant biliary obstruction, especially when the case is further complicated by biliary stones and cholangitis. Associated biliary stones are reported to occur in up to $17 \%$ of patients. ${ }^{[6]}$ When biliary intervention is required, it is generally recommended that a portosystemic shunt (PSS) be performed before the hepaticojejunostomy to avoid the risk of major haemorrhage from the abundant network of venous collaterals around the common bile duct. The added advantages of a PSS are the decreased risk of variceal bleeding and relief of biliary obstruction in $50-78 \%$ of patients. ${ }^{[1,7-9]}$ The disadvantages of this approach are that effective relief of the portal hypertension and $\mathrm{PB}$ cannot be assured with a PSS, which is problematic when there are associated bile duct stones and cholangitis.

Endoscopic interventions are useful as a short-term solution when a patient has associated bile duct stones and cholangitis. They do not provide long-term definitive treatment and complications are significant, especially bleeding from varices in and around the bile ducts. We report on a patient who underwent a successful segment 3 bypass operation for PB after failed endoscopic intervention for biliary stones complicated by episodes of severe cholangitis.

\section{Case report}

A 36-year-old man was admitted to hospital in November 2012 with recurrent cholangitis. At the age of 5 years he had had an oesphageal variceal bleed secondary to an extrahepatic portal vein thrombosis following umbilical vein sepsis caused by a venous catheter used during a neonatal illness. The oesophageal varices were treated with endoscopic band ligation. The last variceal bleed had occurred over a year before his current presentation.

An ultrasound scan demonstrated intrahepatic biliary dilation, and magnetic resonance cholangiopancreatography (MRCP) confirmed compression of the bile duct by venous collaterals. A dominant stricture was present below the biliary confluence (Fig. 1). Endoscopic retrograde cholangiopancreatography (ERCP) confirmed these findings, and in addition a number of small stones and debris were removed from the common bile duct. A plastic biliary stent was placed to relieve the obstruction.

Two weeks later the patient returned with symptoms caused by a blocked stent, which was replaced with two plastic stents. A laparoscopic cholecystectomy was performed to prevent stone propagation. Marked venous collaterals made dissection in the hepatocystic triangle hazardous, and a subtotal cholecystectomy was necessary. Three weeks later he had a further episode of cholangitis. A percutaneous transhepatic cholangiogram (PTC) and placement of an internal external biliary drain was done to provide biliary drainage. A subsequent PTC (Fig. 2) confirmed that the intrahepatic ducts were not involved. This was compatible with a type $1 \mathrm{~PB}$ (Table 1). 
In view of the significant venous collaterals, a standard hepaticojejunostomy was not feasible. To provide a definitive surgical solution to the patient's recurrent cholangitis and stones, an intrahepatic segment 3 bypass was therefore performed. During the operation care was taken to avoid the extensive venous collaterals in the hilar region. The location of the segment 3 portal pedicle was confirmed with intraoperative ultrasound. A wedge of liver parenchyma was resected with a cavitron ultrasonic surgical aspirator (CUSA) and the segment 3 duct was identified (Figs 3 and 4). The duct was opened and flushed to clear debris (Fig. 5). A Roux-en-Y jejunal loop was anastomosed to the segment 3 duct (Figs 5 and 6), and the PTC catheter was left in situ. Histological examination of the liver confirmed 'onion skin' fibrosis in keeping with secondary sclerosing cholangitis.

The patient recovered uneventfully, and the biliary stents and PTC drain were removed 2 weeks after the procedure. A check cholangiogram confirmed good biliary drainage via the segment 3 duct. His jaundice resolved fully and no further episodes of cholangitis had occurred at the time of writing (after 12 months'

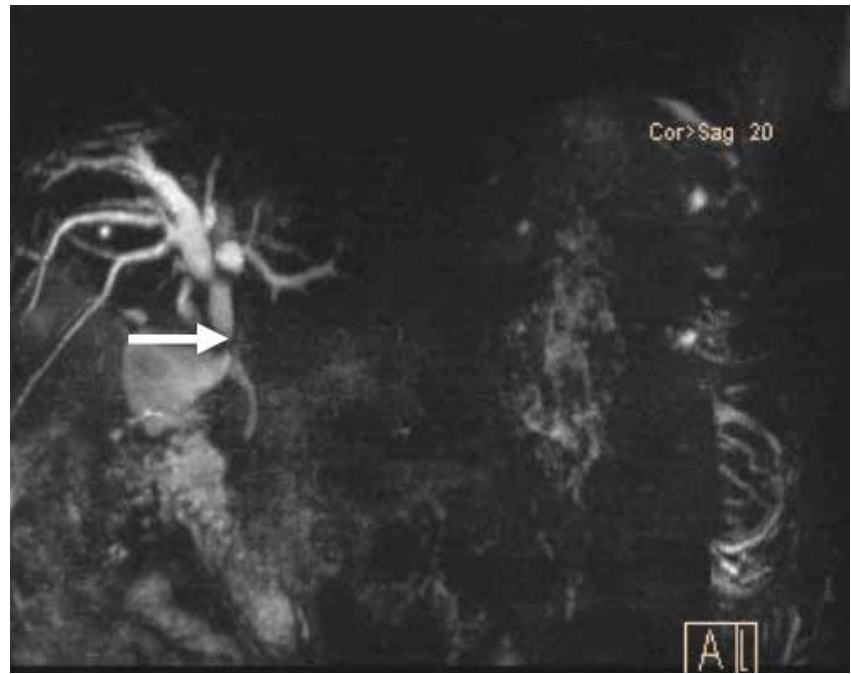

Fig. 1. Magnetic resonance cholangiopancreatogram showing a stricture of the common bile duct (arrow).

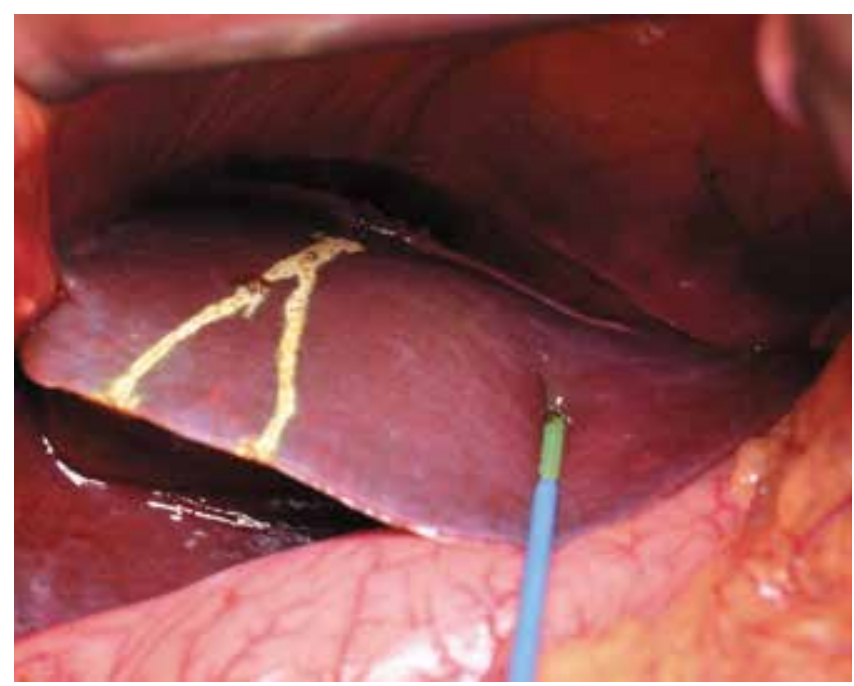

Fig. 3. Left lateral segment. Area to be dissected marked with diathermy. follow-up). His general condition has improved, and he has returned to work.

\section{Discussion}

Most patients with PB remain largely asymptomatic and can be managed conservatively. One-third will develop symptoms including jaundice, pruritus, biliary colic and recurrent cholangitis related to biliary obstruction. These patients warrant careful

Table 1. Classification of portal biliopathy ${ }^{[6]}$

\begin{tabular}{ll}
\hline Type & Findings \\
\hline I & Involvement of extrahepatic duct only \\
II & Involvement of intrahepatic ducts only \\
IIIa & $\begin{array}{l}\text { Involvement of extrahepatic duct and } \\
\text { unilateral intrahepatic ducts }\end{array}$ \\
IIIB & $\begin{array}{l}\text { Involvement of extrahepatic duct and bilateral } \\
\text { intrahepatic ducts }\end{array}$
\end{tabular}

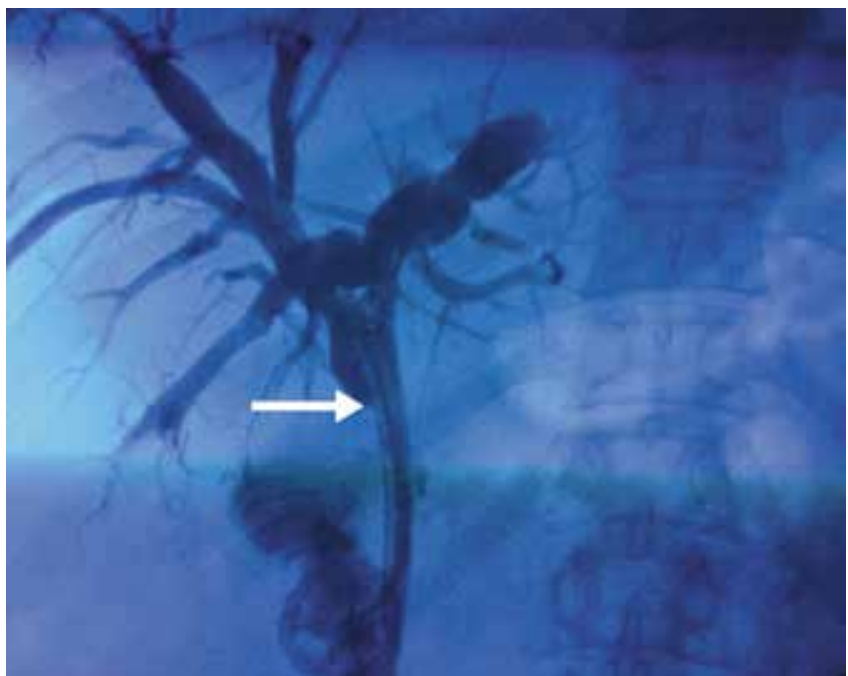

Fig. 2. Percutaneous cholangiogram showing the common bile duct stricture. Plastic biliary stent and percutaneous cholangiogram catheter in situ (arrow).

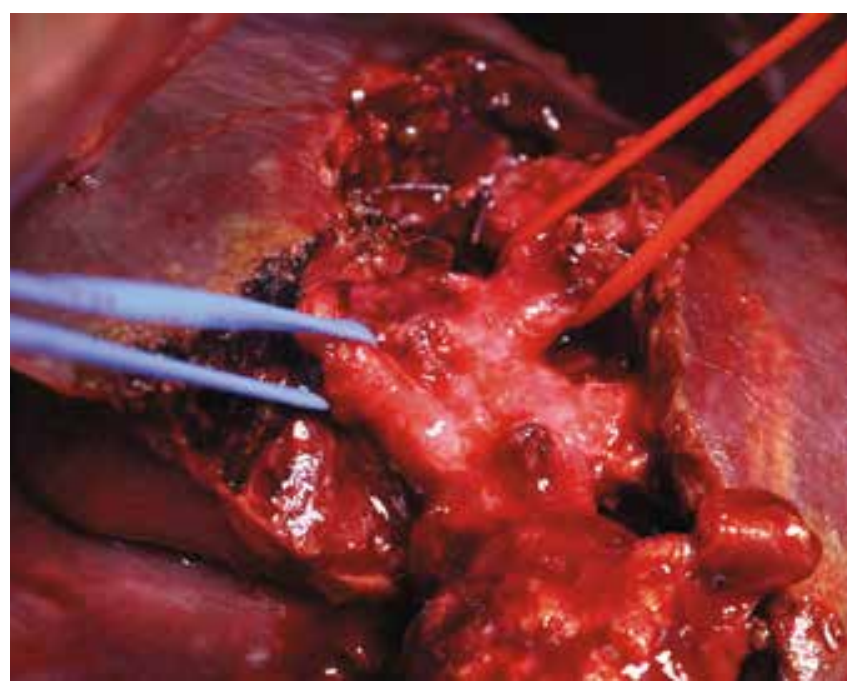

Fig. 4. Segment 3 duct identified. 


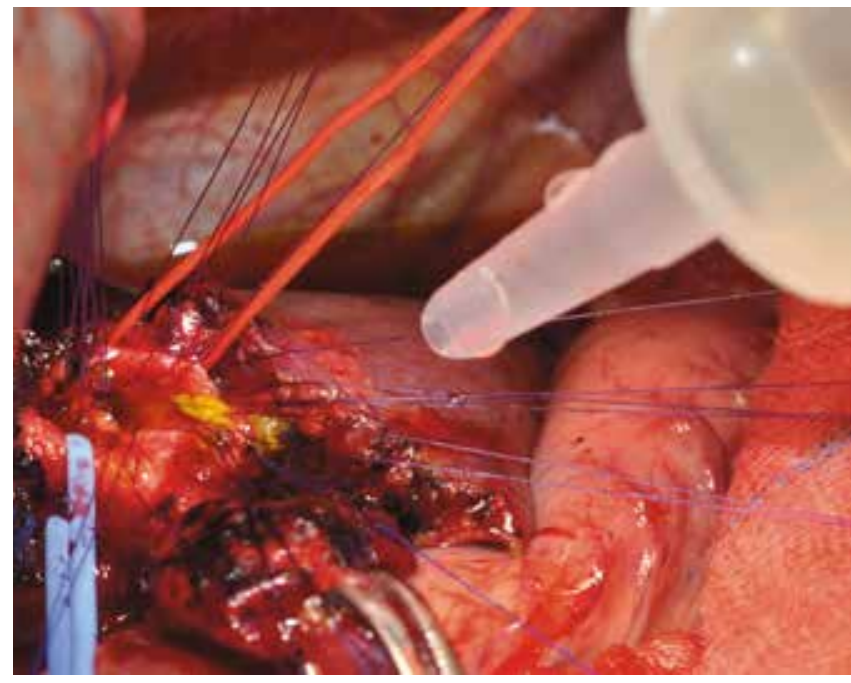

Fig. 5. Sutures placed in the opened segment 3 duct.

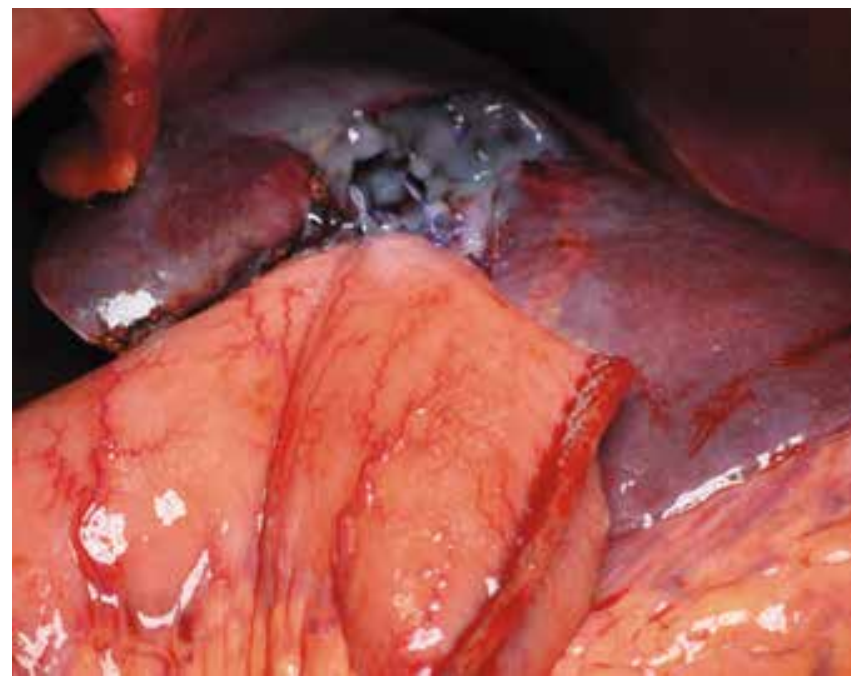

Fig. 6. Anastomosis of the segment 3 duct to the Roux-en-Y jejunal loop.

Table 2. Resolution of biliary obstruction after PSS

\begin{tabular}{|c|c|c|c|c|}
\hline Study & Patients $(N)$ & Intervention & Results & Follow-up \\
\hline Chaudhary et al..$^{[15]}$ & 9 & $\begin{array}{l}\text { Proximal } \\
\text { splenorenal shunt } \\
\text { (+ splenectomy) }\end{array}$ & $\begin{array}{l}\text { Resolution of jaundice } 7 / 9 \text { patients }(77.8 \%) \\
\text { Persistent jaundice requiring biliary enteric } \\
\text { anastomosis } 2 / 9 \text { patients }(22.2 \%)\end{array}$ & Not clear \\
\hline Vibert et al. ${ }^{[9]}$ & 10 & $\begin{array}{l}\text { Retroperitoneal } \\
\text { splenorenal shunt } \\
\text { with jugular vein } \\
\text { interposition }\end{array}$ & $\begin{array}{l}\text { Resolution of jaundice/cholangitis/stones } 4 / 10 \\
\text { patients ( } 40 \%) \\
\text { Persistent jaundice } 3 / 10 \text { patients (30\%) } \\
\text { Recurrent jaundice/cholangitis/stones } 3 / 10 \\
\text { patients ( } 30 \%) \\
\text { Went on to have biliary enteric anastomosis } 5 / 10 \\
\text { patients (50\%) }\end{array}$ & $\begin{array}{l}\text { Mean } 8.2 \text { years } \\
\text { (range } 1.3-18.4)\end{array}$ \\
\hline Agarwal et al. ${ }^{[7]}$ & 37 & $\begin{array}{l}\text { Proximal } \\
\text { splenorenal shunt } \\
(+ \text { splenectomy })\end{array}$ & $\begin{array}{l}\text { Resolution of jaundice } 23 / 37 \text { patients }(62.2 \%) \\
\text { Persistent jaundice } 14 / 37 \text { patients }(7.8 \%) \\
\text { Went on to have biliary enteric anastomosis } 13 / 37 \\
\text { patients }(35.1 \%)\end{array}$ & $\begin{array}{l}\text { Mean } 32 \text { months } \\
\text { (range } 5 \text { - 129) }\end{array}$ \\
\hline
\end{tabular}

investigations to plan for possible treatment strategies. ${ }^{[1]}$ Initial investigations in the assessment of PB involve ultrasonography, computed tomography (in particular to assess segmental atrophy of the liver and the portal venous anatomy), and magnetic resonance imaging/MRCP to delineate the biliary anatomy. The typical cholangiographic features of $\mathrm{PB}$ include indentations and irregularities in the wall of the bile duct, strictures, angulations, ectasia and filling defects. ${ }^{[10,1]}$

Surgical treatment is guided by the extent of the biliary involvement as defined by the Chandra classification (Table 1). Patients with extensive biliary involvement (intra- and extrahepatic or isolated intrahepatic strictures) who are unsuitable for a biliary bypass operation can be offered a PSS, which will resolve the biliary obstruction in about $50 \%$ of cases. With type I involvement the conventional strategy is to perform a PSS first and then to follow this, if required, with a standard hepaticojejunostomy (Table 2). This treatment strategy may not be applicable in patients with cholangitis and associated gallstones, in whom urgent biliary drainage is essential. Endoscopic intervention is important in the initial management and may provide definitive management in some patients. In more severe cases where there is a combination of a significant stricture and multiple intrahepatic stones, endoscopic interventions are less successful. ${ }^{[12-14]}$

There is a paucity of data on the role of segment 3 bypass in $\mathrm{PB}$, and few reports have considered this approach as part of a management algorithm. ${ }^{[9]}$ The advantages of this operation are that the risk of bleeding is minimised by the procedure being performed away from the portal hypertensive field, avoiding the need for a PSS. Also, it is the only safe surgical option in those patients with extensive portal venous thrombosis who, like our patient, are unsuitable for a PSS. It is unclear from the data on the surgical management of $\mathrm{PB}$ what proportion of cases would be suitable for a segment 3 bypass. In a large series, most of the patients who underwent a standard hepaticojejunostomy had type I biliary abnormalities and may have been suitable for a segment 3 bypass. ${ }^{[7,9,15-19]}$ The long-term follow-up of four patients who had a segment 3 bypass showed a high incidence of recurrent stone disease between 7 and 40 months after the surgery. Biliary 
clearance was facilitated by cholangioscopy via the afferent bowel loop. Three $(75 \%)$ of the patients were alive and asymptomatic after a follow-up range of 8 - 9 years. ${ }^{[9]}$

\section{Conclusion}

Careful evaluation of the biliary anatomy and identification of stones is important when considering the best surgical procedure for patients with $\mathrm{PB}$. A segment 3 bypass provides a definitive single-stage surgical procedure that allows biliary decompression and stone removal in one operation. As endoscopic techniques to control oesphageal varices have improved, the need for surgical shunts to prevent bleeding has decreased. A segment 3 bypass should be considered as an alternative procedure to a PSS in patients with $\mathrm{PB}$ with favourable biliary anatomy, especially in the presence of stone disease.

\section{REFERENCES}

1. Chattopadhyay S, Nundy S. Portal biliopathy. World J Gastroenterol 2012;18(43):6177 6182. [http://dx.doi.org/10.3748/wjg.v18.i43.6177]

2. Dilawari JB, Chawla YK. Pseudosclerosing cholangitis in extrahepatic portal venous obstruction. Gut 1992;33(2):272-276. [http://dx.doi.org/10.1136/gut.33.2.272]

3. Sarin SK, Sollano JD, Chawla YK, et al. Consensus on extra-hepatic portal vein obstruction Liver Int 2006;26(5):512-519. [http://dx.doi.org/10.1111/j.1478-3231.2006.01269.x]

4. Rangari M, Gupta R, Jain M, Malhotra V, Sarin SK. Hepatic dysfunction in patients with extrahepatic portal venous obstruction. Liver Int 2003;23(6):434-439. [http://dx.doi org/10.1111/j.1478-3231.2003.00879.x]

5. Dhiman RK, Puri P, Chawla Y, et al. Biliary changes in extrahepatic portal venous obstruction: Compression by collaterals or ischemic? Gastrointest Endosc 1999;50(5):646652. [http://dx.doi.org/10.1016/s0016-5107(99)80013-3]
6. Chandra R, Kapoor D, Tharakan A, Chaudhary A, Sarin SK. Portal biliopathy. J Gastroenterol Hepatol 2001;16(10):1086-1092. [http://dx.doi.org/10.1046/j.14401746.2001.02562.x

7. Agarwal AK, Sharma D, Singh S, Agarwal S, Girish SP. Portal biliopathy: A study of 39 surgically treated patients. HPB (Oxford) 2011;13(1):33-39.

8. Suarez V, Puerta A, Santos LF, Perez JM, Varon A, Botero RC. Portal hypertensive biliopathy: A single center experience and literature review. World J Hepatol 2013;5(3):137-144. [http://dx.doi.org/10.1111/j.1477-2574.2010.00232.x]

9. Vibert E, Azoulay D, Aloia T, et al. Therapeutic strategies in symptomatic portal biliopathy Ann Surg 2007;246(1):97-104. [http://dx.doi.org/10.1097/sla.0b013e318070cada]

10. Malkan GH, Bhatia SJ, Bashir K, et al. Cholangiopathy associated with portal hypertension: Diagnostic evaluation and clinical implications. Gastrointest Endosc 1999;49(3):344-348. [http://dx.doi.org/10.1016/s0016-5107(99)70011-8]

11. Llop E, de Juan C, Seijo S, et al. Portal cholangiopathy: Radiological classification and natural history. Gut 2011;60(6):853-860. [http://dx.doi.org/10.1136/gut.2010.230201]

12. Oo YH, Olliff S, Haydon G, Thorburn D. Symptomatic portal biliopathy: A single centre experience from the UK. Eur J Gastroenterol Hepatol 2009;21(2):206-213. [http://dx.doi. org/10.1097/meg.0b013e3283060ee8]

13. Tighe $M$, Jacobson I. Bleeding from bile duct varices: An unexpected hazard during therapeutic ERCP. Gastrointest Endosc 1996;43(3):250-252. [http://dx.doi.org/10.1016/ s0016-5107(96)70327-9]

14. Mutignani M, Shah SK, Bruni A, Perri V, Costamagna G. Endoscopic treatment of extrahepatic bile duct strictures in patients with portal biliopathy carries a high risk of haemobilia: Report of 3 cases. Dig Liver Dis 2002;34(8):587-591. [http://dx.doi. org/10.1016/s1590-8658(02)80093-7]

15. Chaudhary A, Dhar P, Sarin SK, et al. Bile duct obstruction due to portal biliopathy in extrahepatic portal hypertension: Surgical management. Br J Surg 1998;85(3):326-329. [http://dx.doi.org/10.1046/j.1365-2168.1998.00591.x]

16. Chattopadhyay S, Govindasamy M, Singla P, et al. Portal biliopathy in patients with noncirrhotic portal hypertension: Does the type of surgery affect outcome? HPB (Oxford) 2012;14(7):441-447. [http://dx.doi.org/10.1111/j.1477-2574.2012.00473.x]

17. Gupta S, Singhal A, Goyal N, Vij V, Wadhawan M. Portal biliopathy treated with livingdonor liver transplant: Index case. Exp Clin Transplant 2011;9(2):145-149.

18. Gupta V, Chandra A. Portal biliopathy: Is splenectomy with devascularization really effective? HPB (Oxford) 2013;15(7):559. [http://dx.doi.org/10.1111/j.14772574.2012.00606.x]

19. Poddar U, Borkar V. Management of extra hepatic portal venous obstruction (EHPVO): Current strategies. Trop Gastroenterol 2011;32(2):94-102. 